\title{
A National and Regional Analysis of the Effects of Ageing and Education on Demand for Commercial Health Insurance in China.
}

\section{Xiang Chen}

University College London

Gerard Abou Jaoude ( $\sim$ gerard.jaoude.15@ucl.ac.uk)

University College London

\section{Research Article}

Keywords: Health insurance, Ageing, China, Regional analysis, Fixed effect model, Regression analysis.

Posted Date: May 12th, 2021

DOl: https://doi.org/10.21203/rs.3.rs-492604/v1

License: (c) (1) This work is licensed under a Creative Commons Attribution 4.0 International License.

Read Full License 


\section{Abstract}

Background: Social health insurance (SHI) in China has reached $95 \%$ coverage and facilitated progress toward Universal Health Coverage (UHC). However, elderly populations are currently under-represented, amplifying regional disparities and threatening progress toward UHC. Some households seek commercial health insurance $(\mathrm{CHI})$ to complement $\mathrm{SHI}$. This study is the first to investigate the effect of ageing and education on demand for $\mathrm{CHI}$ by region in China.

Methods: Drawing on 2011 to 2018 data for 31 out of 34 provinces from the China Insurance Yearbook and Statistic Yearbook, fixed effects models were built for national and regional multivariate regression analyses. The analysis included $\mathrm{CHI}$ demand as the dependent variable, education level and elderly dependency ratio as independent variables, and disposable income per capita, $\mathrm{SHI}$ coverage, as well as health expenditure per capita as control variables.

Results: Findings from the national analysis indicate a significant positive relationship between $\mathrm{CHI}$ demand and education level $(17.3, p=0.01)$, elderly dependency ratio $(24.1, p<0.001)$, disposable income per capita (179.5, $p=0.04)$, and health expenditure per capita $(0.12, p<0.001)$. However, no significant association is found between $\mathrm{SHI}$ coverage and $\mathrm{CHI}$ demand. In the regional analysis, a significant positive between education level and $\mathrm{CHI}$ demand is only found for the Eastern region $(29.1, \mathrm{p}<0.05)$. Similarly, a significant positive relationship between the elderly dependency ratio and $\mathrm{CHI}$ demand is observed for the Eastern $(25.9, p<0.05)$ and Central regions $(18.5, p<0.05)$. Of the three control variables investigated, disposable income per capita is not found to have an effect on $\mathrm{CHI}$ demand in any of the three regions.

Conclusions: Results from this study build on existing evidence and draw attention to regional disparities in China, particularly in terms of education, and the resulting effect on $\mathrm{CHI}$ demand. Findings support calls for more elderly-oriented public health policy and insurance reform in China.

\section{Background}

China has the largest population globally and is experiencing one of the fastest rates of ageing. People aged 65 or older accounted for $11.9 \%$ of the total population in 2018 and this is expected to increase to around $26.7 \%$ by 2050 [1]. Compared with high-income countries, the growing elderly population is outpacing economic growth [2]. In addition, rates of aging are heterogeneous across regions and are higher in Eastern China, where income levels are high, compared with other regions such as Western China [1].

Ageing is also resulting in an increasing disease burden more prevalent than in other countries, particularly in terms of chronic non-communicable diseases (NCDs) such as heart disease, chronic obstructive pulmonary disease and dementia [3, 4]. Consequently, overall demand for health services, long-term care and associated medical expenditures are all projected to rise [4]. This introduces challenges that may undo progress made toward Universal Health Coverage (UHC) [5], a United Nations 
Sustainable Development Goal (SDG) which involves access to good quality healthcare for all those that need it, equity and financial risk protection [6, 7]. There is therefore an urgent need to reform the health, social and welfare systems in China to effectively address the health and economic burdens associated with an ageing population $[8,9]$.

Health insurance is one of the key existing mechanisms that could finance and improve access to health services to meet the needs of the ageing population. China's health insurance system is predominantly based on social health insurance (SHI), which includes three main schemes: Urban Employee Basic Medical Insurance (UEBMI, launched in 1998) [10], New Cooperative Medical Scheme (NCMS, launched in 2003) [11], and Urban Resident Basic Medical Insurance (URBMI, launched in 2007) [12]. SHI has enabled substantial progress toward UHC in the country $[3,13]$, reaching $95 \%$ coverage [1].

However, despite the high coverage of SHI, large disparities exist for the elderly and the scheme does not sufficiently cover diseases common among older populations [9]. SHI predominantly focusses on catastrophic diseases such as cancer, acute myocardial infarction and other acute conditions [13-15], which can lead to large economic shocks and financial hardship. Given that the elderly often have less disposable income and higher levels of healthcare utilization, they are more likely to experience financial hardship from medical expenses [2,3] - not only from catastrophic diseases, but also from chronic conditions for which care is not covered by SHI. The existing SHI scheme is therefore unlikely sufficient to ensure continuing progress toward UHC in China.

Commercial health insurance $(\mathrm{CHI})$ is an alternative sought by households to complement $\mathrm{SHI}$ and cover against health conditions which are not included in the latter [16]. Currently, the fledgling introduction of $\mathrm{CHI}$ in China mainly focuses on urban areas, providing additional coverage to individuals that are able to afford it. Rural areas have only recently become a priority [17]. However, while $\mathrm{CHI}$ presents a potential opportunity for addressing the health needs of elderly populations, the demand for $\mathrm{CHI}$ in China has largely been underestimated $[16,18]$. To date, the growing $\mathrm{CHI}$ market has been inaccessible and paid insufficient attention to elderly groups with the greatest need [15]. This is due to several reasons, one of which is the lack of knowledge about $\mathrm{CHI}$, especially among the elderly with lower levels of education. High SHI coverage has been achieved because of its compulsory or semi-compulsory nature. By comparison, $\mathrm{CHI}$ is voluntary and thus much less known among the elderly [15]. There is insufficient education and knowledge to distinguish between the role and function of $\mathrm{CHI}$ and $\mathrm{SHI}$, and a belief that it is not necessary to have supplementary insurance due to $\mathrm{SHI}$ coverage [18].

\subsection{Review of the literature}

A number of studies have analysed the relationship between ageing, education and $\mathrm{CHI}$ in China. Table 1 below provides a summary of the analyses, presenting the data sources, methods used, and results of each study. Based on existing evidence, key independent variables include age [16, 19], education level $[15,20]$, income level $[21,22]$, SHI coverage $[23,24]$ and health expenditures [19]. 
Table 1

Summary of existing studies investigating the relationship between ageing, education and $\mathrm{CHI}$ demand.

\begin{tabular}{|c|c|c|c|c|c|}
\hline \multirow{2}{*}{$\begin{array}{l}\text { Authors } \\
\text { (year) }\end{array}$} & \multirow[t]{2}{*}{ Data } & \multirow[t]{2}{*}{ Method } & \multirow{2}{*}{$\begin{array}{l}\text { Geographical } \\
\text { focus }\end{array}$} & \multicolumn{2}{|c|}{ Results: the effect on $\mathrm{CHI}$} \\
\hline & & & & Ageing & Education \\
\hline $\begin{array}{l}\text { Jin et. } \\
\text { al. } \\
(2016)\end{array}$ & $\begin{array}{l}\text { China Health and } \\
\text { Retirement Longitudinal } \\
\text { Survey } 2011 \text { and } 2013\end{array}$ & $\begin{array}{l}\text { Multinomial } \\
\text { logit } \\
\text { regression }\end{array}$ & National & $\begin{array}{l}\text { Negative } \\
\text { effect }\end{array}$ & Positive effect \\
\hline $\begin{array}{l}\text { Fu \& Su } \\
(2016)\end{array}$ & $\begin{array}{l}2011 \text { China Household } \\
\text { Finance Survey (CHFS) }\end{array}$ & $\begin{array}{l}\text { Binary logit } \\
\text { regression } \\
\text { model }\end{array}$ & National & $\begin{array}{l}\text { Negative } \\
\text { effect }\end{array}$ & $\begin{array}{l}\text { Positive effect } \\
\text { in urban } \\
\text { households } \\
\text { but a negative } \\
\text { effect in rural } \\
\text { households }\end{array}$ \\
\hline $\begin{array}{l}\text { Liu \& } \\
\text { Wang } \\
\text { (2012) }\end{array}$ & $\begin{array}{l}\text { China Health and nutrition } \\
\text { survey data from 2000- } \\
2006\end{array}$ & $\begin{array}{l}\text { Bivariate } \\
\text { Probit with } \\
\text { partial } \\
\text { observability }\end{array}$ & National & $\begin{array}{l}\text { Positive } \\
\text { effect }\end{array}$ & $\begin{array}{l}\text { Positive effect } \\
\text { in urban } \\
\text { households } \\
\text { but no } \\
\text { significant } \\
\text { effect in rural } \\
\text { households }\end{array}$ \\
\hline $\begin{array}{l}\text { Suo et } \\
\text { al. } \\
(2015)\end{array}$ & $\begin{array}{l}\text { Panel data of } 31 \text { provinces } \\
\text { in China from 2004-2013 }\end{array}$ & $\begin{array}{l}\text { Fixed } \\
\text { effects } \\
\text { model }\end{array}$ & $\begin{array}{l}\text { National and } \\
\text { Regional }\end{array}$ & - & Positive effect \\
\hline $\begin{array}{l}\text { Qi, et } \\
\text { al. } \\
(2018)\end{array}$ & $\begin{array}{l}\text { Panel data of } 31 \text { provinces } \\
\text { in China from } 2006-2016\end{array}$ & $\begin{array}{l}\text { Gaussian } \\
\text { mixture } \\
\text { modelling } \\
(\text { GMM) }\end{array}$ & National & $\begin{array}{l}\text { Positive } \\
\text { effect }\end{array}$ & Positive effect \\
\hline $\begin{array}{l}\text { Chen et } \\
\text { al. } \\
(2019)\end{array}$ & $\begin{array}{l}\text { Cross-sectional data of } 31 \\
\text { provinces in China in } 2017\end{array}$ & $\begin{array}{l}\text { Multivariate } \\
\text { linear } \\
\text { regression }\end{array}$ & National & $\begin{array}{l}\text { Positive } \\
\text { effect }\end{array}$ & Positive effect \\
\hline $\begin{array}{l}\text { Ying et } \\
\text { al. } \\
(2007)\end{array}$ & $\begin{array}{l}\text { A household survey } \\
\text { conducted in four small } \\
\text { cities in Sichuan and } \\
\text { Shandong provinces in } \\
\text { China }\end{array}$ & $\begin{array}{l}\text { Contingent } \\
\text { valuation } \\
\text { methods }\end{array}$ & Regional & $\begin{array}{l}\text { Negative } \\
\text { effect }\end{array}$ & Positive effect \\
\hline $\begin{array}{l}\text { Ni and } \\
\text { Feng } \\
(2018)\end{array}$ & $\begin{array}{l}\text { Panel data of } 31 \text { provinces } \\
\text { in China from } 2009-2015\end{array}$ & $\begin{array}{l}\text { Cross- } \\
\text { sectional } \\
\text { fixed effects } \\
\text { model }\end{array}$ & National & $\begin{array}{l}\text { Ageing } \\
\text { can } \\
\text { promote } \\
\mathrm{CHI} \\
\text { demand } \\
\text { to a } \\
\text { certain } \\
\text { extent }\end{array}$ & $\begin{array}{l}\text { No significant } \\
\text { effect }\end{array}$ \\
\hline
\end{tabular}

Ageing and $\mathrm{CHI}$ demand in China 
Some studies report that age has a negative effect on the demand for $\mathrm{CHI}$ in China [15, 21, 25]. Fu and Su (2016) [25] conducted a multinomial logit regression using data from the China Health and Retirement Longitudinal Survey 2011 and 2013 and found that older populations were less likely to buy CHI. This is explained by the fact that $\mathrm{CHI}$ is relatively new and less well understood by the elderly with lower levels of education given the complex design of some CHI plans. Fu and Su (2016) [25] focussed on the population group aged 45 years old and above and conducted their study from the perspective of household financial burden. They use a binary logit regression model and data from the 2011 China Household Finance Survey. They find that each family adjusts their asset allocation according to their specific situation. As an important part of household financial asset allocation, the demand for $\mathrm{CHI}$ will also change with the financial burden experienced. Similarly to the negative relationship reported by Jin et al. (2016) [15], Fu and Su (2016) [25] found that holding other variables constant, the probability of buying $\mathrm{CHI}$ will reduce by $1.8 \%-2.4 \%$ as household age increases by 1 year. This is again explained by the role of knowledge and education, where older residents may resist various insurance products because of a lack of understanding compared with younger individuals that are more likely to accept insurance as a risk management tool. In addition, for most types of health insurance, younger individuals are offered lower premiums, thus stimulating demand for $\mathrm{CHI}$ among young people while lowering demand among the elderly.

In contrast, using bivariate Probit with partial observability and China Health and Nutrition Survey data for 2000-2006, Liu and Wang (2012) [16] find that the probability of buying CHI increases with age. Moral hazard was considered and the purchasing behavior of $\mathrm{CHI}$ was divided into two decision-making processes: the potential demand-side decision-making for $\mathrm{CHI}$ and the supply-side decision-making of insurance companies. On the supply-side, insurance companies may reject individuals with higher health risks and health expenditures such as the elderly. On the demand-side the effect of adverse selection [26], where individuals with higher health risk are more willing to buy $\mathrm{CHI}$ [27], is combined with positive selection [28] where risk averse individuals are more likely to buy long-term care insurance but less likely to use it because of efforts to maintain good health. Another study by Qi et al. (2018) [19] also reports a positive effect of ageing on $\mathrm{CHI}$ demand using Gaussian mixture modelling and panel data for 31 provinces in China from 2006-2016. Their results are explained by the increased health burden associated with ageing. Lower health risks among young people means they are less likely to purchase $\mathrm{CHI}$ compared with the elderly that are more likely to incur medical expenses due to increased hospitalization and outpatient visits. Moreover, the growing trend of 'empty nesters' in China, older parents whose children have moved out of the household, also promotes the demand for $\mathrm{CHI}$ and longterm care insurance in particular.

\section{Education and $\mathrm{CHI}$ demand in China}

All except for one study by $\mathrm{Ni}$ and Feng (2018) [29] report that education has a significant positive effect on $\mathrm{CHI}$ demand. Chen et al. (2019) [30] conducted a multivariate linear regression using cross-sectional data for 31 provinces in China in 2017 and found that a higher education level is associated with higher demand for $\mathrm{CHI}$. On the one hand, individual health status is affected by the surrounding environment 
and social context. Education levels are generally higher in 'mega cities' such as Beijing and Shanghai, although pollution and work pressures may also be higher, which have adverse effects on the health status of residents - thus promoting the demand for health care and health insurance. However, findings also show that the higher the level of education, the better the understanding of how $\mathrm{CHI}$ functions as well as associated claims and reimbursement processes.

Suo et al. (2015) [20] built fixed effects models based on panel data from 31 provinces in China for 2004-2013. They identify that education level is one of the most important influencing factors of $\mathrm{CHI}$ development while considering regional differences. A higher level of education is suggested to lead to higher risk awareness, as well as improved understanding of the nature of insurance products and longterm health planning at the individual level. In addition, results from the regional regressions highlight a more pronounced effect of education level on $\mathrm{CHI}$ demand in the Central and Western regions than in the Eastern region. This is explained by a declining marginal effect. As the overall education level in the Eastern region has risen to a higher level, the marginal effect of education on $\mathrm{CHI}$ demand is smaller. In contrast, in the Western region where the education level is comparatively low, the marginal effect of education level on $\mathrm{CHI}$ demand is more significant.

Liu and Wang (2012) report that education level has a positive effect on $\mathrm{CHI}$ demand among urban households while no significant effect is observed in rural households [16]. This is because insurance companies often carry out student group insurance programs in schools in urban areas, but in rural areas, schools generally do not have similar plans due to lower purchasing power. Fu and Su (2016) [25] argue that education level has a positive effect among urban households and a negative effect in rural households, as urban households are relatively more independent and the mutual influence of household decision-making is small. The acceptance of insurance products by households depends on the education level and life experience of each household's decision-maker. However, rural households may rely on each other's behaviours to a larger extent due to more social interaction and close communication, while also possessing a poor understanding of insurance products.

However, to our knowledge no study has investigated ageing, education and $\mathrm{CHI}$ demand together while taking into account variations across regions in China. This paper aims to fill this gap by investigating the effects of ageing and education on CHI demand across regions in China between 2011 and 2018, ultimately to help inform governments and insurance companies in formulating policy reform.

\section{Methods}

\subsection{Data}

Sufficient data was available on dependent, independent and control variables, to generate a sample of 31 out of 34 provinces in China for the years 2011 to 2018. The data sources used were the China Insurance Yearbook and Statistic Yearbook for each province [31-32]. Both yearbooks are annual, nationwide and based on cross-sectional surveys. Data for all the variables selected and described below 
are collected by sampling surveys, except for $\mathrm{CHI}$ premium which is provided by insurance companies in different provinces. Data on the elderly dependency ratio and education level were collected through a $1 \%$ population sampling survey for the year 2015 and the national population change survey which also accounts for about $1 \%$ of the total population for other years. Data on disposable income and health expenditure were collected using stratified, multi-stage sampling surveys, from a sample that is rotated periodically to ensure representativeness.

The data from the yearbooks are collected based on resident population instead of registered population, avoiding bias associated with population mobility. In addition, to minimise potential bias, only data for urban populations were considered in this study because $\mathrm{CHI}$ in rural areas developed relatively late and has grown at a slower pace. Current $\mathrm{CHI}$ market data are therefore predominantly available for urban areas. In turn, to reduce the influence of population sizes in different provinces, all variables were used in per capita or percentage form.

\subsection{Selected variables, justification and expect effect on $\mathrm{CHI}$ demand}

Average $\mathrm{CHI}$ premium per capita for each province was used as the dependent variable to quantify $\mathrm{CHI}$ demand. $\mathrm{CHI}$ premium is considered a predominant measure of $\mathrm{CHI}$ demand and has been previously used in a number of similar studies $[21,29]$. The premium refers to the amount that people pay to maintain $\mathrm{CHI}$ cover.

Education and ageing were the two independent variables used (Table 2). Ageing at the provincial level was measured using the elderly dependency ratio, an international demographic measure of ageing represented by the ratio between the number of the elderly dependents (aged 65 years old and above) and the total labor force (aged 15 to 64 years old) in a population [33]. As the overall age of a country or region increases, the ratio can reflect the increasing health and social needs associated with an ageing population. It is calculated as follows:

elderly dependency ratio $=\frac{\text { number of people aged } 65 \text { or over }}{\text { number of people aged } 15-64}$

The percentage of the total population that received higher education was used to represent the overall education level of each province. Higher education was defined as possessing a college degree or above. This is a widely used measure of the overall education level of a region in China and is consistent with previous studies $[29,30]$.

\section{Table 2: Justification and expected effect of independent and control variables on $\mathrm{CHI}$ demand}




\begin{tabular}{|c|c|c|c|c|}
\hline Category & $\begin{array}{l}\text { Variable } \\
\text { name }\end{array}$ & Description & $\begin{array}{l}\text { Expected } \\
\text { effect }\end{array}$ & Justification \\
\hline \multicolumn{5}{|c|}{ Independent variables } \\
\hline Ageing & edr & $\begin{array}{l}\text { Elderly } \\
\text { dependency } \\
\text { ratio (\%) }\end{array}$ & + & $\begin{array}{l}\text { Elderly groups are likely to demand health care } \\
\text { services more frequently, which could result in } \\
\text { increased demand for CHI. }\end{array}$ \\
\hline $\begin{array}{l}\text { Education } \\
\text { level }\end{array}$ & edu & $\begin{array}{l}\text { Ratio of } \\
\text { people with } \\
\text { higher } \\
\text { education } \\
\text { level (\%) }\end{array}$ & + & $\begin{array}{l}\text { A higher level of education may be associated } \\
\text { with a better awareness and understanding of } \\
\text { risk, the function of health insurance products, } \\
\text { and be associated with higher disposable } \\
\text { income. Together, these may result in higher } \\
\text { demand for CHI. }\end{array}$ \\
\hline \multicolumn{5}{|c|}{ Control variables } \\
\hline $\begin{array}{l}\text { Purchasing } \\
\text { power }\end{array}$ & dinc & $\begin{array}{l}\text { Disposable } \\
\text { income per } \\
\text { capita } \\
\text { (yuan). }\end{array}$ & + & $\begin{array}{l}\text { Higher disposable income provides } \\
\text { households with more flexibility on how much } \\
\text { they allocate to health and increases the } \\
\text { likelihood that CHI premiums are affordable- } \\
\text { both of which can result in increased demand } \\
\text { for } \mathrm{CHI} \text {. }\end{array}$ \\
\hline $\begin{array}{l}\text { SHI } \\
\text { coverage }\end{array}$ & shi & $\begin{array}{l}\text { Ratio of } \\
\text { number of } \\
\text { SHI } \\
\text { participants } \\
\text { to total } \\
\text { population } \\
(\%)\end{array}$ & + or - & $\begin{array}{l}\text { SHI coverage may have a promoting or } \\
\text { substituting effect on demand for } \mathrm{CHI} \text {. }\end{array}$ \\
\hline $\begin{array}{l}\text { Health } \\
\text { Expenditure }\end{array}$ & hexp & $\begin{array}{l}\text { Health } \\
\text { expenditure } \\
\text { per capita } \\
\text { (yuan) }\end{array}$ & + or - & $\begin{array}{l}\text { Higher health expenditure indicates higher } \\
\text { willingness to spend on health, which may } \\
\text { result in higher demand for } \mathrm{CHI} \text {. However, } \\
\text { increased health expenditure per capita may } \\
\text { also indicate a higher disease burden that can } \\
\text { dis-incentivise CHI companies from offering } \\
\text { coverage, which would result in a negative } \\
\text { relationship being observed with CHI demand. }\end{array}$ \\
\hline
\end{tabular}

Disposable income, also known as disposable personal income (DPI), was used as one of three control variables (Table 2). It is considered a key economic indicator and influencing factor of $\mathrm{CHI}$ demand, representing the amount of money available for households to spend and save after accounting for income taxes. In other words, the income that households are free to use. Many studies have identified the positive effect of disposable income on $\mathrm{CHI}$ demand in China [15, 21-22]. When disposable income is low, the limited income available to households is sufficient only to meet necessary living expenses [21, 22]. Currently, $\mathrm{CHI}$ mainly targets higher socioeconomic population groups in China [13]. Premiums are therefore usually high and few people are able to afford them. As disposable income per capita increases, for example following economic growth, more households will retain a surplus of income after the consumption of necessities. This enables households to adjust their asset allocation and spend more on health, which could result in increased demand for $\mathrm{CHI}$. 
The number of SHI participants expressed as a percentage of the total population is widely used in representing SHI coverage and was used as a control variable [15]. However, there is a lack of consensus on whether $\mathrm{SHI}$ participation positively or negatively effects $\mathrm{CHI}$ demand. Potential effects can be grouped into two categories: promoting and substituting effects. In the latter, SHI participants will be less likely to purchase $\mathrm{CHI}$, demonstrating a possible substituting effect between $\mathrm{SHI}$ and $\mathrm{CHI}$ [15]. For example, Liu, Wang and Bian (2010) [34] report a net substituting effect of SHI on CHI, suggesting the substituting effect outweighs the promoting effect. Given that some of China's health insurance reforms are nascent, $\mathrm{CHI}$ companies have not sufficiently adopted a supplemental role in the health system and continue to promote SHI substitutes. Considering the compulsory nature and the advantage of fee remission of $\mathrm{SHI}$, the inevitable result is that competing $\mathrm{CHI}$ products are crowded out. In contrast, $\mathrm{Li}$ (2011) [22], Wang (2011) [23] and Liu and Liu (2014) [24] find that SHI can boost CHI demand. Wang (2011) [23] argues that instead of crowding out, SHI has driven the development of $\mathrm{CHI}$ and the competition has greatly contributed to $\mathrm{CHI}$. SHI improves household health, wealth, and increases individual awareness of health insurance. In addition, the degree of protection provided by SHI is limited, which provides opportunities for $\mathrm{CHI}$ development - especially in disability care, other debilitating diseases, an income loss compensation. $\mathrm{CHI}$ companies can also cooperate with $\mathrm{SHI}$ institutions to develop various health insurance products to meet the needs of different residents through information sharing mechanisms.

The third control variable included was health expenditure per capita. Similarly to SHI participation, there are differing views on whether health expenditure per person has a positive or negative effect on $\mathrm{CHI}$ demand. On the one hand, health expenditure per capita can be a proxy for people's willingness to spend on health. The more individuals spend on health, the more likely they are to purchase $\mathrm{CHI}$ products [17]. On the other hand, high per capita health expenditure may be due to a higher disease burden which translates into greater financial risk for $\mathrm{CHI}$ companies. In this case, while individual may be more willing to participate in $\mathrm{CHI}$ plans, insurance companies may reject them to avoid potential high-risk claims [16]. While this is not a demand-side problem, if people with high health expenditure are rejected by insurance companies the data may result in a negative association being observed between health expenditure and $\mathrm{CHI}$ demand.

\subsection{Econometric model specification and set-up}

A multivariate regression model was selected, which has been widely used in similar studies of insurance demand. The log form of disposable income per capita was taken to study the effect of the rate of change of disposable income per capita on $\mathrm{CHI}$ premium per capita.

The basic model was specified as follows:

$\operatorname{chi}=\beta_{0}+\beta_{1} e d u+\beta_{2} e d r+\beta_{3} \ln (\operatorname{dinc})+\beta_{4} \operatorname{shi}+\beta_{5} \operatorname{hexp}+u$ 
where signs show the direction of relationships, and the significance of $\beta 1$ and $\beta 2$. $\beta 1$ and $\beta 2$ respectively measure the effect of education levels and of ageing on $\mathrm{CHI}$ demand, which is expected to be significantly positive in both cases.

As the time period considered in the analysis is relatively short (eight years), the unit root test was not conducted due to reduced validity when timeframes shorter than 20 years are used $[20,35]$. The influence of heteroscedasticity was mitigated by the use of robust standard error [36]. In addition, it was considered that the overall education level of each province could be a potential endogenous variable. This is because parental education levels have a positive effect on children's education attainment and motivation $[37,38]$. Individuals' education level may therefore be influenced by their parents' education, which is difficult to quantify at the provincial level due to population mobility. Based on the premise that parents' education levels are unlikely to change much over the time, a fixed effects model, which can control for each province's unobserved and time-invariant characteristics that are potentially correlated with the included dependent variables, was considered to overcome potential sources of endogeneity [39]. Pooled Ordinary Least Squares (OLS), fixed effects models and random effects models were tested. The selection of a fixed effects model as the main model was decided based on the $F$ test and Hausman test results shown in Table 3, which suggested that a fixed effects model is more efficient than pooled OLS and random effects model.

\section{Table 3: Results of the F Test and Hausman Test}

\begin{tabular}{|llll|}
\hline Model & Type of Test & p-value & Selection of Model \\
\hline Fixed effects model \& Pooled OLS & F test & 0.000 & Fixed effects model \\
\hline Random effects model \& Fixed effects model & Hausman test & 0.001 & Fixed effects model \\
\hline
\end{tabular}

Furthermore, separate regressions using regional samples were conducted to account for key differences between regions. Regional disparities in terms of public resources, economic, education and health resources are substantial in China, which can influence $\mathrm{CHI}$ demand. For instance, households in regions with more developed economies may earn higher incomes and possess more savings, thus making it more likely that they will spend more on health compared with less economically developed areas [16]. In turn, regions with better education resources may have a more favourable environment overall for the development of $\mathrm{CHI}$. Residents in such regions may have a better understanding of $\mathrm{CHI}$ and awareness of insurance as a means of protection against risk, which can lead to an increase in the demand for $\mathrm{CHI}$ [40]. With regards to health resources, regions with limited health resources may have poorer health infrastructure and medical facilities that hinder the provision of some healthcare services, thus constraining demand for $\mathrm{CHI}[35]$.

\section{Results}




\subsection{Descriptive statistics}

The final sample of 31 provinces and eight years (2011-2018) generated a total of 248 observations. National summary statistics for each dependent, independent and control variable are presented in Table 4, while the average values of variables are presented for each of the three regions in Table 5. Substantial differences are observed between the Eastern, Central and Western regions. The Central and Western regions are largely comparable with one another across all variables. In both regions, average $\mathrm{CHI}$ premium, education levels, disposable income, $\mathrm{SHI}$ participation and health expenditures per capita are lower than the national average. By comparison, the average values for all variables in the Eastern region are higher than the national average, and the average $\mathrm{CHI}$ premium (280.4) is more than double that of the Central and Western regions (129.5 and 129.7 respectively). However, it is important to note that the average elderly dependency ratio is similar in the Eastern (13.8) and Central (13.8) regions, and greater than in the Western region (12.8).

Table 4

Summary statistics of analysis variables, national (2011-2018)

\begin{tabular}{|llllll|}
\hline Variable & Number of observations & Mean & Standard deviation & Minimum & Maximum \\
\hline chi & 248 & 184.5 & 211.78 & 13.84 & 1487.24 \\
\hline edr & 248 & 13.46 & 3.16 & 6.71 & 22.69 \\
\hline edu & 248 & 12.4 & 6.87 & 2.14 & 45.95 \\
\hline dinc & 248 & 22750.17 & 9125.16 & 9746.81 & 64182.64 \\
\hline shi & 248 & 54.71 & 29.08 & 14.41 & 100.00 \\
\hline hexp & 248 & 1425.76 & 542.18 & 424.1 & 3475.81 \\
\hline
\end{tabular}

Table 5

Mean of analysis variables, regional (2011-2018)

\begin{tabular}{|llll|}
\hline Variable (mean) & Eastern & Central & Western \\
\hline chi & 284.2 & 129.54 & 129.67 \\
\hline edr & 13.8 & 13.78 & 12.77 \\
edu & 16.65 & 10.25 & 9.88 \\
\hline dinc & 30681.21 & 19586.29 & 17189.9 \\
\hline shi & 64.53 & 47.3 & 49.96 \\
\hline hexp & 1590.58 & 1356.49 & 1313.74 \\
\hline
\end{tabular}

\subsection{National regression}


Results from the national fixed effects model are presented in Table 6. The findings indicate a significant positive relationship between $\mathrm{CHI}$ premium or demand and education level $(17.3, p=0.01)$, elderly dependency ratio $(24.1, p<0.001)$, the natural logarithm of disposable income per capita $(179.5, p=0.04)$ and health expenditure per capita $(0.12, p<0.001)$. However, no significant relationship is observed between $\mathrm{SHI}$ coverage and $\mathrm{CHI}$ demand.

Table 6

Fixed effects model regression results, national

\begin{tabular}{|lllllll|}
\hline Variable & Coefficient & Std. Error & t statistic & \multicolumn{2}{c|}{ p-value } & \multicolumn{2}{c|}{$95 \%$ Conf. Interval } \\
\hline edu & 17.25763 & 6.268167 & 2.75 & 0.010 & 4.45633 & 30.05894 \\
\hline edr & 24.14004 & 4.238383 & 5.70 & 0.000 & 15.48411 & 32.79597 \\
\hline In(dinc) & 179.4894 & 56.74849 & 3.16 & 0.040 & 63.59354 & 295.3853 \\
\hline hexp & 0.1170826 & 0.0227496 & 5.15 & 0.000 & 0.070622 & 0.1635435 \\
\hline shi & -0.4205171 & 0.4542482 & -0.93 & 0.362 & -1.34822 & 0.5071815 \\
\hline R-squared & & 0.7015 & & & & \\
\hline Number of obs & & 248 & & & & \\
\hline
\end{tabular}

As the ratio between the number of people with higher education and the total population increases so does $\mathrm{CHI}$ premium per capita, which is as expected (Table 2). For each percentage point increase in the education level ratio, $\mathrm{CHI}$ premium per capita increases by 17.3 Yuan. Similarly, as expected, CHI premium per capita increases as the elderly dependency ratio increases. For each percentage point increase in the elderly dependency ratio, $\mathrm{CHI}$ premium per capita increases by 24.1 Yuan. In terms of control variables, as disposable income per capita increases by $1 \%, \mathrm{CHI}$ premium per capita increases by 179.5 Yuan, and for each 1 Yuan increase in health expenditure per capita the $\mathrm{CHI}$ premium per capita increases by 0.12 Yuan.

\subsection{Regional Regression}

Overall, the regional regression results presented in Table 7 are largely consistent with findings using the national sample (Table 6), although there are differences in the statistical significance and magnitude of coefficients between regions. Education level only has a significant positive effect on $\mathrm{CHI}$ demand in the Eastern region (29.1, p < 0.05), with no significant effect in the Central and Western regions. A significant positive relationship is also found between the elderly dependency ratio and $\mathrm{CHI}$ demand in the Eastern and Central regions (25.9, $p<0.05$ and $18.5, p<0.05$ respectively), but not for the Western region. With regards to control variables, the effect of disposable income per capita is not significant in any of the three regions. By comparison, while health expenditure per capita does not have a significant effect on $\mathrm{CHI}$ demand in the Eastern region, a significant positive effect is observed for the Central and Western regions $(0.11, p<0.001$ and $0.13, p<0.05$ respectively). Unlike national results where $\mathrm{SHI}$ participation is 
not found to have any effect, a significant positive effect is observed for the Central region $(0.84, p<0.05)$ but not for the Eastern or Western regions.

Table 7

Fixed effects model regression results, regional

\begin{tabular}{|c|c|c|c|}
\hline Variable & Eastern & Central & Western \\
\hline \multirow[t]{2}{*}{ edu } & $29.13303^{*}$ & 4.346216 & 5.743751 \\
\hline & $(3.50)$ & $(0.97)$ & (1.79) \\
\hline \multirow[t]{2}{*}{ edr } & $25.88773^{\star}$ & $18.52523^{*}$ & 20.97697 \\
\hline & $(3.60)$ & $(4.16)$ & $(1.89)$ \\
\hline \multirow[t]{2}{*}{$\ln (\operatorname{dinc})$} & 361.37 & 63.39149 & 84.65527 \\
\hline & $(-0.91)$ & $(1.41)$ & $(2.16)$ \\
\hline \multirow[t]{2}{*}{ hexp } & 0.071042 & 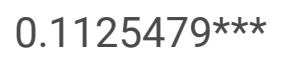 & $0.130161^{*}$ \\
\hline & $(2.13)$ & $(4.13)$ & $(4.13)$ \\
\hline \multirow[t]{2}{*}{ shi } & -0.915067 & $0.8352056^{\star}$ & -0.3317401 \\
\hline & $(-1.10)$ & $(4.46)$ & $(-1)$ \\
\hline R-squared & 0.7266 & 0.8256 & 0.5359 \\
\hline F-statistic & 20.73 & 167.43 & 68.42 \\
\hline Number of obs & 88 & 80 & 80 \\
\hline
\end{tabular}

\section{Discussion}

This paper presents the first analysis in which the effects of both education and ageing on $\mathrm{CHI}$ demand in China are investigated across years while taking into account regional differences. Overall, results from the analysis support existing evidence which suggests that the effects of education and ageing on $\mathrm{CHI}$ demand are positive and statistically significant. The results also build on previous evidence, highlighting how regional disparities result in varying demand for $\mathrm{CHI}$. These findings have wider implications for policy makers involved in health and health financing reform, insurance companies and other researchers. This section will expand on and interpret the results, as well as discuss key limitations of the study.

Findings from the national and regional analyses demonstrate that an overall improvement in education levels can increase $\mathrm{CHI}$ demand in China. Based on the literature, the main reasons for this are likely that higher education levels generally contribute to a better understanding of the function and need for $\mathrm{CHI}$ or 
insurance more widely, a better awareness of health risk mitigation and an improved ability to understand insurance claims processes and insurance products [30]. Individuals with higher education levels are therefore more likely to purchase $\mathrm{CHI}$, and may also be better able to afford $\mathrm{CHI}$ premiums. However, the increase in the education level of a province is mainly driven by the improved education of young people [41]. In turn, younger populations with higher education level are more likely to purchase $\mathrm{CHI}$ for themselves as well as for their older relatives or dependents [41].

Taking into account regional differences, the positive effect of education level on $\mathrm{CHI}$ demand is significant in the Eastern region but not significant in the Central and Western regions. A possible reason for this is that there are more insurance companies in Eastern China, compared with other regions, which provide a number of $\mathrm{CHI}$ products to meet the various needs of consumers with different characteristics [40]. Individuals living in the Eastern China that want to buy $\mathrm{CHI}$ can therefore find the insurance products and services they need more readily than other regions. In contrast, $\mathrm{CH}$ is less developed in Central and Western regions where people are less likely to find $\mathrm{CHI}$ products and services suited to their needs and will instead resort to other financial protection mechanisms [22]. Education level may therefore have a larger effect on $\mathrm{CHI}$ demand in Eastern China than other regions where there is less formal or service sector employment and less $\mathrm{CHI}$ products are available. A second reason that a significant positive relationship was only found between education and $\mathrm{CHI}$ demand in the Eastern region could be that there is more awareness of $\mathrm{CHI}$ in the Eastern region [42]. Individuals that are better aware of $\mathrm{CH}$ and understand $\mathrm{CHI}$ products as well, as how they can mitigate health risks, due to higher education levels are more likely to choose $\mathrm{CHI}$ as a risk protection tool [30]. It is also important to note that the likely reason why a significant effect is observed for education levels in the national sample, despite no significant effect in Central and Western regions, is the growth of $\mathrm{CHI}$ markets in Eastern China. Eastern China, which is more developed than the national average across all of the variables considered in this analysis, leads to the development and growth of the $\mathrm{CHI}$ markets nationally $[14,43]$ - though this currently may not be sufficiently pronounced to result in a significant effect when regions are considered separately.

The national sample results on the effect of education on $\mathrm{CHI}$ demand presented in this paper are consistent with the wider literature [20,30]. However, the regional sample results differ from a study carried out by Suo et al. (2015) [20]. The latter report that the effect of education on $\mathrm{CHI}$ demand is more significant in the Central and Western regions than in Eastern China. This divergence of results may be due to the different samples used. Suo et al. (2015) [20] included both urban and rural populations in their sample, while the analyses in this paper focussed only on urban populations to minimise potential bias in the results given that current $\mathrm{CHI}$ market data are predominantly from urban areas. Central and Western regions are comprised of a higher rural population than Eastern China and overall education levels in rural areas are substantially lower than in urban areas $[1,44]$. By including rural populations, the average education level therefore decreases, and the difference of education levels between the Central and Western regions compared with Eastern China would be larger. Subsequently, the marginal effect of education levels on $\mathrm{CHI}$ demand in Central and Western China would be amplified, which may result in a higher significance level for the effect of education than in the Eastern China. 
In line with previous studies $[19,30]$ the analyses presented in this paper find that ageing has a significant positive effect on $\mathrm{CHI}$ demand. This can be explained by the fact that as individuals age, the probability of experiencing chronic disease increases as well as the likelihood of incurring associated medical expenses due to hospitalization and outpatient visits $[4,40]$. Given that $\mathrm{CHI}$ can improve access to healthcare services, and in some cases financial risk protection from medical expenses, the demand for $\mathrm{CHI}$ increases accordingly with age $[4,40]$. In addition, the increasing trend of 'empty nesters' in China, where children move out of parental households, also boosts $\mathrm{CHI}$ demand. This is because $\mathrm{CHI}$ can reduce the burden for carers associated with supporting dependents. As the number of empty nesters increases, $\mathrm{CHI}$ demand is therefore also expected to grow [19].

This paper presents the first analysis of $\mathrm{CHI}$ demand that considers the differences in ageing across regions in China. Placing these findings in the literature is therefore challenging. The regional regression results show that the effect of ageing on $\mathrm{CHI}$ demand is significant in the Eastern and Central regions but not in Western China. The reason for this could be due to the difference in the elderly dependency ratio between regions. As shown in the summary statistics in Table 4, the average elderly dependency ratio in Eastern and Central China is 13.8 which is higher than in the Western region (12.8). Individuals in the Eastern and Central regions are therefore more likely to experience chronic disease and associated expenses, and have developed a better understanding of the risks associated with ageing as well as how the operation and functions of $\mathrm{CHI}$ can mitigate these risks [20]. As the elderly dependency ratio continues to rise, people living in Eastern and Central China are therefore more likely to respond to the changes by purchasing $\mathrm{CHI}$ products.

In terms of control variables, the significant positive effect of health expenditure per capita on $\mathrm{CHI}$ demand in the national sample likely reflects that the willingness to pay and prioritise health over other spending from the demand-side [17] is greater than the effect of risk aversion among insurance companies from the supply side [16]. Findings are similar for the Central and Western regions, but no significant effect is observed for Eastern China. This may be because the average $\mathrm{CHI}$ premium is comparatively higher in Eastern China $[43,45]$, which may deter consumers that experience a substantial disease burden from purchasing $\mathrm{CHI}$.

Disposable income per capita also has a significant positive effect on $\mathrm{CHI}$ demand in the national sample, with the largest coefficient, which suggests that increases in overall household income drive demand for $\mathrm{CHI}$ [20]. However, disposable income per capita is not found to have a significant effect on $\mathrm{CHI}$ demand in any of the regions. This may be because, first, income levels in the Eastern and Central regions are already high, and an increase in disposable income per capita may therefore not translate into increased $\mathrm{CHI}$ demand as income is allocated for other consumption [20]. Second, because a previous study has reported that the effect of income on $\mathrm{CHI}$ demand is greater in rural than in urban areas [17]. Given that this study is based on urban populations the effect of income may be diminished, particularly in the Western region that has the lowest income and a high rural population. Overall, these results suggest that disparities in income levels, and not only in education levels, may be driving inequitable demand for $\mathrm{CHI}$ in China. 
Unlike health expenditure and disposable income per capita, $\mathrm{SHI}$ participation is not found to have a significant effect on $\mathrm{CHI}$ demand in the national sample regression, which is likely because the promoting and substituting effects offset each other $[15,22]$. By comparison, regional regression results show that $\mathrm{SHI}$ participation has a significantly positive effect on $\mathrm{CHI}$ demand in the Central region. This may be because the degree of ageing in the Central region is similar to the Eastern region, while $\mathrm{CHI}$ demand in Central China lags behind levels of demand in the Eastern region. Considering that an increase in SHI participation can spread knowledge of health insurance and also improve awareness of the availability of $\mathrm{CHI}$, when coverage of $\mathrm{SHI}$ increases, understanding of $\mathrm{CHI}$ may also improve resulting in increased demand $[15,40]$.

Overall, however, some key limitations should be considered when interpreting the results presented. First, the concept of moral hazard, which is a key factor when studying health insurance, is considered only at the theoretical level and is not explicitly included in the empirical analysis. The implication of this is that the effect of health expenditure on $\mathrm{CHI}$ demand observed from the data may be underestimated. If people living in provinces with high health expenditures per capita due to higher health risks and disease burden are rejected by insurance companies, the results from the data may misrepresent the latter as lower demand for $\mathrm{CHI}$. Second, although this paper focuses only on urban populations to minimise possible bias, this reduces the sample size which in turn could affect the power and generalisability of the analysis and results. A more representative sample should be used in future studies as additional $\mathrm{CHI}$ market data becomes available. Third, attitudes to risk, or risk preferences, have a significant effect on demand for $\mathrm{CHI}$ and insurance in general [16] but these are not considered in this analysis.

Nonetheless, the findings from this paper can help inform health policy and insurance reform, with implications for government and insurance companies. This study suggests that while $\mathrm{CHI}$ demand is increasing alongside ageing to supplement existing $\mathrm{SHI}$ coverage, the government must consider the education level of different regions to redress regional disparities and prevent further inequity as $\mathrm{CHI}$ coverage expands. There is a need to implement elderly focussed health insurance reform, for example through further expansion and consolidation of the existing SHI packages of services $[46,47]$ so that SHI better caters for an ageing population that currently has to resort to $\mathrm{CHI}$. Alongside SHI reform, the significant effect of disposable income on $\mathrm{CHI}$ demand found at a national level calls for the government and insurance companies to work together to lower $\mathrm{CHI}$ premiums and make $\mathrm{CHI}$ available and affordable for households in regions where coverage is low. However, further research and policy discussions are needed to explore cost-effective and sustainable solutions to motivate $\mathrm{CHI}$ companies to extend complementary coverage among the elderly [48]. Either way, these analyses support calls for education interventions for the elderly within a policy framework such as the World Health Organisation's 'healthy ageing'. The latter recommends making basic education, including health education and health literacy, available throughout the life-course [49] - which can also help progress toward life-long education that forms a part of the SDG on education [7]. Such basic education could cover the health insurance system and different mechanisms available to protect against health risks, which may benefit the least educated most. The government could, for example, emulate aspects of Japan's policy, which 
has with some success used life-long education as a tool to alleviate both the social and household burdens associated with ageing [50].

\section{Conclusions}

This paper used 2011 to 2018 data from the China Insurance Yearbook and Statistic Yearbook to conduct the first national and regional analyses investigating the effect of both education and ageing on the demand for commercial health insurance $(\mathrm{CHI})$ in China. Results from the national and regional analyses demonstrate that both education and ageing have a significant positive effect on $\mathrm{CHI}$ demand, which is consistent with wider literature. However, findings from this paper draw attention to the regional disparities in education and its effect on $\mathrm{CHI}$ demand after controlling for health expenditure per capita, disposable income per capita and social health insurance coverage. The results support calls for more elderly-oriented public health policy and insurance reform in China to redress inequities as $\mathrm{CHI}$ coverage expands.

\section{Abbreviations}

$\mathrm{CHI}$ : Commercial health insurance

NCD: Non-communicable disease

NCMS: New cooperative medical scheme

OLS: Ordinary least squares

SDG: Sustainable development goal

SHI: Social health insurance

UEBMI: Urban employee basic medical insurance

UHC: Universal health coverage

\section{Declarations}

Ethics approval and consent to participate

Not applicable. Ethics approval was not required for this secondary data analysis.

\section{Consent for publication}

Not applicable.

\section{Availability of data and material}


The datasets analysed during the current study are available in: (1) National data: China Statistical Yearbook from the National Bureau of Statistics of China (http://www.stats.gov.cn/tjsj/ndsj/2019/indexeh.htm), (2) Provincial data: Annual data by province from the National Bureau of Statistics of China (https://data.stats.gov.cn/english/easyquery.htm?cn=E0103), and (3) CHI premium: Provincial Statistical Yearbooks from the National Bureau of Statistics of China (http://nj.tjj.beijing.gov.cn/nj/main/2019-tjnj/zk/indexch.htm).

\section{Competing interests}

The authors declare that they have no competing interests.

\section{Funding}

No funding was received or used for this work.

\section{Authors' contributions}

Conceptualization: XC and GAJ. Methodology: XC, GAJ. Formal analysis: XC. Writing-original draft preparation: XC and GAJ. Writing-review and editing: XC and GAJ. Supervision: GAJ. All authors have read and approved the final version of the manuscript.

\section{Acknowledgements}

None.

\section{References}

1. National Bureau of Statistics. China Statistic Yearbook, Retrieved from http://www.stats.gov.cn/tjsj/ndsj/2019/indexch.htm. <background-color:\#66FF66;uverticalalign:super;>2019</background-color:\#66FF66;uvertical-align:super;>

2. Yu, T.. Research on China's aging population and elderly consumption. Jilin University. 2013

3. Barber, S. L., \& Rosenberg M. Aging and Universal Health Coverage: Implications for the Asia Pacific Region. Health Systems \& Reform. 2017, 154-158. doi: DOI:10.1080/23288604.2017.1348320.

4. Teng, H., Cao, Z., Liu, J., Liu, P., Hua, W., Yang, Y. and Xiong, L. Health Status and Burden of Health Care Costs Among Urban Elderly in China. Asia-Pacific Journal of Public Health. 2015, 27(2S).

5. Zhou M, Wang H, Zeng X, Yin P, Zhu J, Chen W, Li X, Wang L, Wang L, Liu Y, Liu J. Mortality, morbidity, and risk factors in China and its provinces, 1990-2017: a systematic analysis for the Global Burden of Disease Study 2017. The Lancet. 2019 Sep 28;394(10204):1145-58.

6. World Health Organisation. Universal Health Coverage: Fact Sheet: World Health Organisation, Retrieved from https://www.who.int/news-room/fact-sheets/detail/universal-health-coverage-(uhc). 2019 
7. United Nations. Transforming our world: the 2030 Agenda for Sustainable Development, Retrieved from https://sustainabledevelopment.un.org/post2015/transformingourworld. 2015

8. Yip W, Fu H, Chen AT, Zhai T, Jian W, Xu R, Pan J, Hu M, Zhou Z, Chen Q, Mao W. 10 years of healthcare reform in China: progress and gaps in universal health coverage. The Lancet. 2019 Sep 28;394(10204):1192-204.

9. Wang, X., \& Chen, P. Population ageing challenges health care in China. The Lancet. 2014, 383(9920).

10. State Council. Decisions of the state council on establishing the urban employee essential medical scheme, Retrieved from http://big5.gov.cn/gate/big5/www.gov.cn/banshi/200508/04/content_20256.htm. 1998

11. State Council. Decisions of the state council on establishing a new rural cooperative health care system, Retrieved from http://www.gov.cn/zwgk/2005-08/12/content_21850.htm. 2013

12. State Council. Instructions on establishing the urban employee essential medical scheme, Retrieved from http://www.gov.cn/zwgk/2007-07/24/content 695118.htm<uvertical-align:super;>-</uverticalalign:super;><uvertical-align:super;></uvertical-align:super;><background-color:\#66FF66; uverticalalign:super;>2007</background-color:\#66FF66;uvertical-align:super;>

13. Dong, K. Medical insurance system evolution in China. China Economic Review. 2009, 20(4), $591-$ 597. doi: 10.1016/j.chieco.2009.05.011

14. Zheng, R. M. \& Hua, J. The Degree of Coordination between Commercial Medical Insurance and Social Medical Insurance in China. Insurance Studies. 2013, (04):101-109.

15. Jin, Y., Hou, Z., \& Zhang, D. Determinants of Health Insurance Coverage among People Aged 45 and over in China: Who Buys Public, Private and Multiple Insurance. PLOS ONE. 2016, 11(8), e161774. doi: 10.1371/journal.pone.0161774.

16. Liu, H. and Wang, J. An Empirical Analysis of Private Health Insurance Ownership in China. China Economics Quarterly. 2012, 11(04):1525-1548.

17. Liu, H. L. Demand Elasticity Analysis of Commercial Health Insurance in Mainland China and Comparison between Its Regional Difference. Chongqing Technol Business University (Nat Sci Ed). 2015, 32(04):49-54.

18. Ye, A. Z., Lu, F., Huang, W. H. \& Liang, J. (Eds.). On the Commercial Health Insurance Demand Preference and Insure Behaviors Characteristics of City Dweller-Take the Nanning City for Example. Paper presented at the 2013 China International Conference on insurance and risk management; 2013; Kunming, Yunnan China.

19. Qi, Z. P., Xu, Y. F. and Hu, J. B. An Analysis on Commercial Health Insurance Demands Based on Demographic Structure. Insurance Studies. 2018, 2018-05-20(05):45-55.

20. Suo, L. Y., Wanyan, R. Y, \& Chen, T. A Research on the Uneven Development of Health Insurance and Its Reasons. Insurance Study. 2015, (01), 42-53.

21. Ying, X., Hu, T., Ren, J., Chen, W., Xu, K. \& Huang, J. Demand for private health insurance in Chinese urban areas. Health Economics. 2007, 16(10), 1041-1050. doi: 10.1002/hec.1206. 
22. Li, B. Analysis on the factors influencing the demand of commercial health insurance in China. Journal of insurance professional college (Bimonthly). 2011, 25(2), 26-29.

23. Wang, $X$. Social medical insurance, market structure and the development of commercial health insurance in China. Insurance Studies. 2011, (07), 35-41.

24. Liu, R., \& Liu, H. X. How can commercial health insurance and social health insurance be mutually beneficial under the universal health insurance system? Finance and Economy. 2014, 5, 108-111.

25. Fu, Y., \& Su, Z. Analysis on the Influencing Factors of Commercial Insurance Demand in China's urban and rural families. Journal of Harbin University of Commerce. 2016; (05), 17-28.

26. Sapelli, C., \& Vial, B. Self-selection and moral hazard in Chilean health insurance. Journal of Health Economics. 2003, 22(3).

27. Long, S. Prescription drugs and the elderly: issues and options. Health affairs (Project Hope). 1994, 13(2).

28. Finkelstein, A., \& McGarry, K. Multiple Dimensions of Private Information: Evidence from the LongTerm Care Insurance Market. American Economic Review. 2006, 96(4).

29. Ni, L., \& Feng, G. The Analysis on the Influence Factors of Commercial Health Insurance Demand Based on the Model of Cross-sectional Fixed Effect. China Health Economics. 2018, 37(3), 27-30. doi: 10.7664/CHE20180308.

30. Chen, Q., Zhang, Q., \& Liu, J. Study on the Social Security Role of Commercial Health Insurance in China under the Background of Aging. Technology and Industry. 2019, 19(9), 150-155.

31. China Insurance Regulatory Commission \& Editorial board of China Insurance Yearbook (20122019), China Insurance Yearbook, Editorial board of China Insurance Yearbook. 2019

32. [Dataset] China National Bureau of Statistics (2020), Statistic yearbooks, [https://data.stats.gov.cn/easyquery.htm?cn=E0103], accessed: August 2020

33. Harwood R. H, Sayer A. A. \& Hirschfeld. M. Current and future worldwide prevalence of dependency, its relationship to total population, and dependency ratios. Bulletin of the World Health Organization. 2004, 82(4).

34. Liu, F., Wang, X., \& Bian, H. Empirical analysis of influence factors on the commercial health insurance's development. Chinese Journal of Health Policy. 2010, 03(9), 38-44. doi: 10.3969/j.issn.1674-2982.2010.09.009.

35. Zhu, J. \& Wu, Z. H. An Empirical Analysis of Influencing Factors of Commercial Health Insurance Demand in China. Journal of Xihua University (Philoophy \& Social Science). 2018, 37(2), 58-65.

36. Woolridge, J. Introduction to Econometrics. 2009

37. Acharya, N., \& Joshi, S. Influence of Parents' Education on Achievement Motivation of Adolescents. Indian Journal Social Science Researches. 2009, 6(1), 72-79.

38. Hortaçsu, N. Parents' Education Level, Popularity, Individual Cognitions, and Academic Performance: An Investigation with Turkish Children. Nuran Hortaçsu. 2010, 155(2).

39. Baltagi, B. H. Econometric analysis of panel data (237-256). 2005 
40. Ding, S., \& Wu, X. Discussion on the provincial differences in the development of commercial health insurance in China. Shanghai Insurance. 2018 (07), 39-42

41. Zhu, M. L. \& Gui, Z. X. Public and Private Health Insurance in Medical Expenditure Financing-An Analysis based on 2003-2012 China's Provincial Panel Data of Urban Areas. Insurance Studies. 2014, (6), 96-104. doi: DOl:10.13497/j.cnki.is.2014.06.011.

42. Yang, B., \& Jiang, R. Y. Study on Regional Development Differences of commercial health insurance and its influencing factors - Analysis Based on needs perspective. Journal of Southeast University (Philosophy and Social Science). 2018, 20(3).

43. Zhang, M. L., Lan, S. Q., Luo, Q., Li, D. S., Li, L. Z \& Wei, J. S. Research on the Regional Development Status of Health Insurance in China from 2006 to 2015. Chinese Health Economics. 2018, 37(04), 33-36.

44. Lu, W., Yang, M., \& Wang, Y. Urban-rural income gap, education inequality and government investment in Education. Economic and social systems comparison. 2015, (03), 20-33.

45. Li, Q. Analysis on the Influencing Factors of Commercial Health Insurance Premium - Based on the comparison of Hubei, Beijing and Shanghai. Southern Finance. 2009, 7, 55-59.

46. Meng, Q., Fang, H., Liu, X., Yuan, B., \& Xu, J. Consolidating the social health insurance schemes in China: towards an equitable and efficient health system. Lancet. 2015, 386(10002).

47. Li, C., Tang, C., \& Wang, H. Effects of health insurance integration on health care utilization and its equity among the mid-aged and elderly: evidence from China. International Journal for Equity in Health. 2019, 18(1).

48. Yang, L. C. Several issues on the sustainability of social insurance system. Financial science. 2020, 72-79.

49. World Health Organization. World Health Report on Ageing and Health. Retrieved from https://apps.who.int/iris/bitstream/handle/10665/186463/9789240694811_eng.pdf?sequence=1. 2015

50. Wang, Z. G., \& Xu, J. P. How to make open education for the elderly more attractive? Enlightenment of the Japanese Open University to the running of China's Open University for the aged. China distance education. 2020, 52-59. 